\title{
Venecia en Flandes, a propósito del lienzo de Jan Ykens de Alejandro y Hefestión con la familia de Darío
}

\author{
Venice in Flanders, regarding Jan Ykens and his \\ Alexander and Hephaestion Consoling the Family of Darius
}

\begin{abstract}
Matías Díaz Padrón ${ }^{1}$
Académie Royale d'Archéologie et d'Histoire de l'Art de Belgique Instituto Moll. Centro de investigación en pintura flamenca
\end{abstract}

Resumen: Jan Ykens ha sido identificado como el autor del lienzo de Alejandro y Hefestión con la familia de Darío. De este desconocido pintor flamenco sólo se tenía noticia a través de varias obras firmadas en diversas iglesias de Bélgica. Poco más se sabe de él, debido, en parte, a que su trabajo ha quedado diluido en la saga familiar de pintores a la que pertenece. El estilo de esta nueva pintura concuerda con las fórmulas de sus obras firmadas.

Palabras clave: Jan Ykens, pintura flamenca, siglo XVII, Alejandro Magno, Dario.

Abstract: Jan Ykens has been identified as the author of Alexander and Hephaestion Consoling the Family of Darius. About this unknown Flemish painter, there are only a few works of art signed and located in several churches in Belgium. No much more is known about him because of the Family painters that he belongs to. His production is mixed with others from his family. Nevertheless, in this case, the style of this new painting fits well with that works signed by Jan Ykens in Belgium.

Key Words: Jan Ykens, Flemish painting, 17th century, Alexander the Great, Darius.

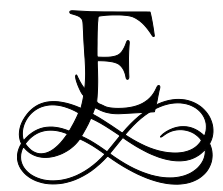

I lienzo de Alejandro y Hefestión con la familia de Darío llegó a la colección Epiarte procedente del mercado internacional, como

1 (i) https://orcid.org/0000-0002-5137-7583

(C) 2019 Philostrato. Revista de Historia y Arte 
obra de autor anónimo². (Fig. 1) El análisis estético, técnico y comparativo de la composición con otras pinturas firmadas por Jan Ykens nos ha llevado a catalogarla a su nombre, a pesar de ser un pintor del que se conocen escasas obras, pero cuyo estilo está en consonancia con el de la pintura que aquí se estudia.

Este hallazgo nos invita a exponer toda la información de la que se dispone de la personalidad y arte de Jan Ykens, cuyas referencias bibliográficas se limitan a estudios de Philippe Rombouts y Théodore van Lerius en el siglo XIX. Más recientes son las recogidas tanto por Elisabeth Dhanens, como por Jan de Maere y Marie Wabbes en sus diccionarios generales sobre pintores flamencos del siglo XVII. A ellas se suma la de Bernadette Bodson en otro diccionario centrado en los pintores belgas desde el siglo XVI a la actualidad $y$, en los últimos años, la investigación de Maartje Witlox en relación al trabajo conjunto de los pintores del siglo XVII ${ }^{3}$. A esta escasez de datos sobre Jan Ykens hay que añadir la dificultad de diferenciarle de otros miembros de su familia dedicados a la pintura. Así, en estos repertorios de autores constan, además de él, Catharina II (Amberes, 1659-1756?), Charles I (Amberes, 1682-Bruselas?, después de 1718), Charles II (Bruselas, 1719-1753), Frans (Amberes, 1601-Bruselas?, 1693), Jan Peter (1673- Bruselas, 1721?) y Peter Ykens (Amberes, 1648-1695).

Jan Ykens nació en Amberes en 1613 y falleció en la misma ciudad hacia $1680^{4}$. Se formó con su padre, Melsen Ykens, un prestigioso escultor que influyó en el gusto de Jan por las arquitecturas provistas de esculturas, tan frecuentes en los fondos de sus composiciones. De hecho, Jan también está recogido como escultor en los diccionarios anteriormente mencionados, pero, por el momento, no se conocen obras suyas de esta naturaleza.

Las fuentes insisten en su amistad con David Ryckaert III, con quien se considera que perfeccionó sus estudios de pintura. Sin embargo, no se han advertido influencias de este pintor en la obra de Jan Ykens, quien alcanzó la maestría en la guilda de San Lucas de Amberes en 1639-16405.

Las pinturas que se conservan firmadas por él están estrechamente vinculadas con la temática clásica y con la Biblia. Aunque también hay noticias

\footnotetext{
2 L. 85 x 135cm. Christie's Nueva York, (17-X-2006, no 212); Bonhams Londres, (6-XII-2017, no 57 ).

3 Philippe Rombouts y Théodore van Lerius, Les Liggeren et autres archives historiques de la Gilde Anversoise de Saint Luc, II, (Anvers-La Haye, 1864-1876), pp. 100-101; Elisabeth Dhanens, Inventaris van het kunstpatrimonium van de provincie Oost-Vlaanderen, Temse, IV, (Dendermonde, Gent, 1961), pp. 125-126; Jan de Maere \& Marie Wabbes, Illustrated dictionary of the 17th century flemish painters, II, (Bruxelles: La Renaissance du Livre, 1994); Bernadette Bodson, "Ykens Jan (Ijkens) Anvers, 1613 après 1679", en VV.AA., Le Dictionnaire des Peintres Belges du XIVe siècle à nos jours. L-Z, (Bruxelles: La Renaissance du Livre, 1995), p. 1204; Maartje Witlox, "Vele handen maken licht werk", Mauritshuis in Focus, 1, vol. 18, (2005), pp. 16-26.

${ }^{4}$ Bernadette Bodson indica que Jan Ykens falleció después de 1679. Sin embargo, RKD recoge que su última obra está fechada en 1680 y considera que falleció entre ese año y 1699: Bodson, "Ykens Jan...", p. 1204; RKD, "Johannes ikens". (En " web: https://rkd.nl/nl/explore/artists/record?query=Jan+Ykens\&start=7, consultada: 1-III-2019)

${ }^{5}$ Rombouts y Van Lerius, Liggeren, II, pp. 100-101.
} 


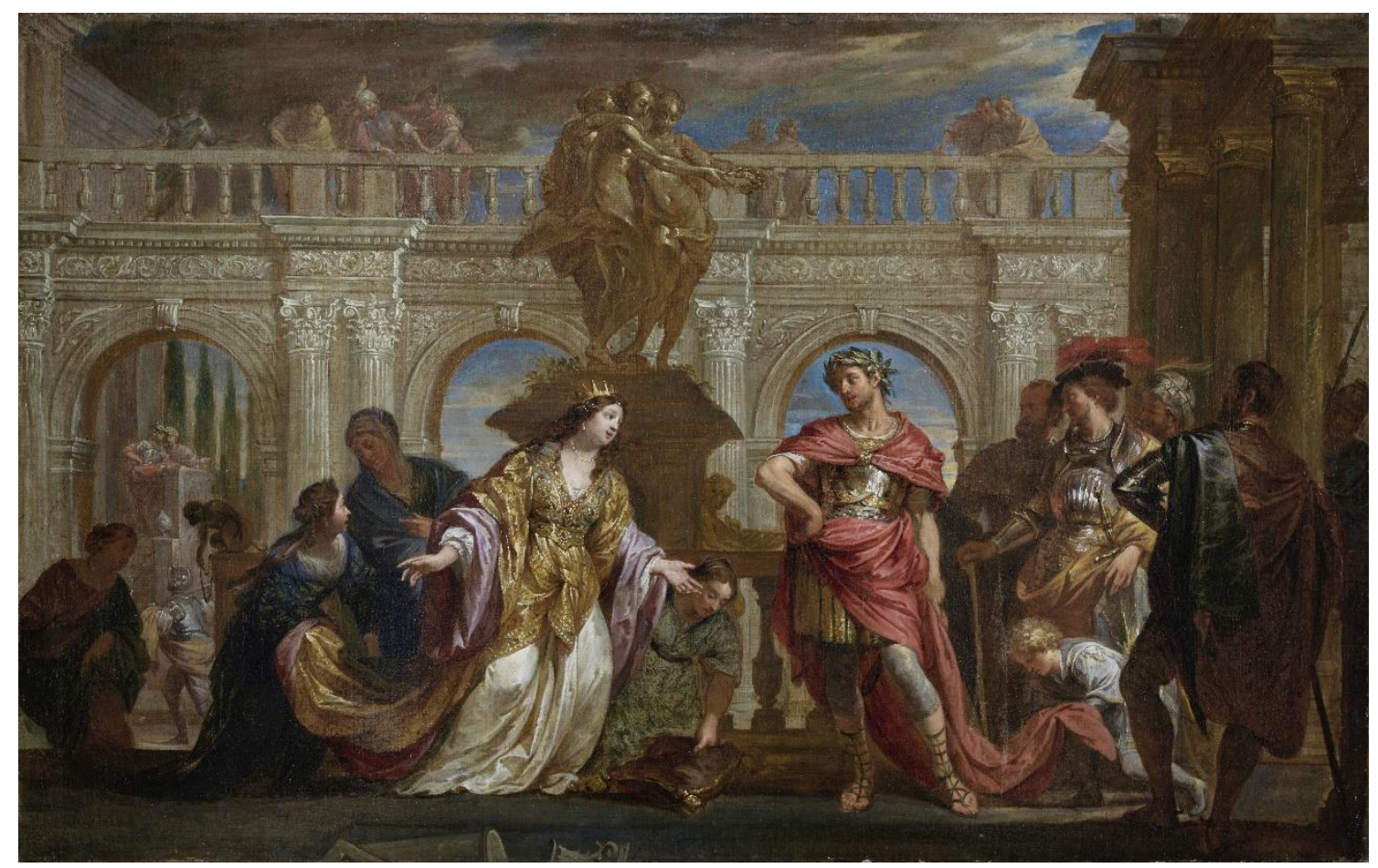

Fig. 1. Jan Ykens, Alejandro y Hefestión con la familia de Darío, Madrid, colección Epiarte@

de que ha practicado el retrato ${ }^{6}$. Sus fondos son marcos de rica arquitectura ideal que adorna la narrativa y son, para nosotros, la marca más personal de su producción. Esto es lo que dio motivo para pensar en la autoría de este pintor para el lienzo de Alejandro y Hefestión con la familia de Darío.

Una atracción desbordante del Renacimiento veneciano es lo más inmediatamente visible en las obras de Jan Ykens. Es un rasgo evidente, no sólo en los modelos arquitectónicos sino también en la riqueza y esplendor de los colores en un espacio de notable signo teatral. A juzgar por lo que conocemos de su obra, esta inclinación hacia un comedido Barroco es característica de la generación del último tercio del siglo XVII en Flandes, como sutil reacción al impetuoso Barroco de Rubens.

Las figuras de Jan Ykens se mueven con pausada distinción y elegancia en medio de fachadas con columnas, arcos y frisos de gran riqueza ornamental. Es difícil encontrar otro pintor tan comprometido con la arquitectura, la escultura y el relieve.

En el lienzo de Alejandro y Hefestión con la familia de Darío advertimos el mismo sentimiento estético y visual que el pintor despliega en tantas otras

\footnotetext{
${ }^{6}$ En 1679 está siendo contratado por Johanna de Winter, viuda de Artus van Uffels, para realizar su retrato y el de sus hijos. Contrato firmado en Amberes el 10 de noviembre de 1679 delante del notario J. F. Haecx. Erik Duverger, Antwerpse Kunstinventarissen uit de Zeventiende Eeuw, 10, Fontes Historiae Neerlandicae, (Brussel: 1999), pp. 498-499, no 3433.
} 


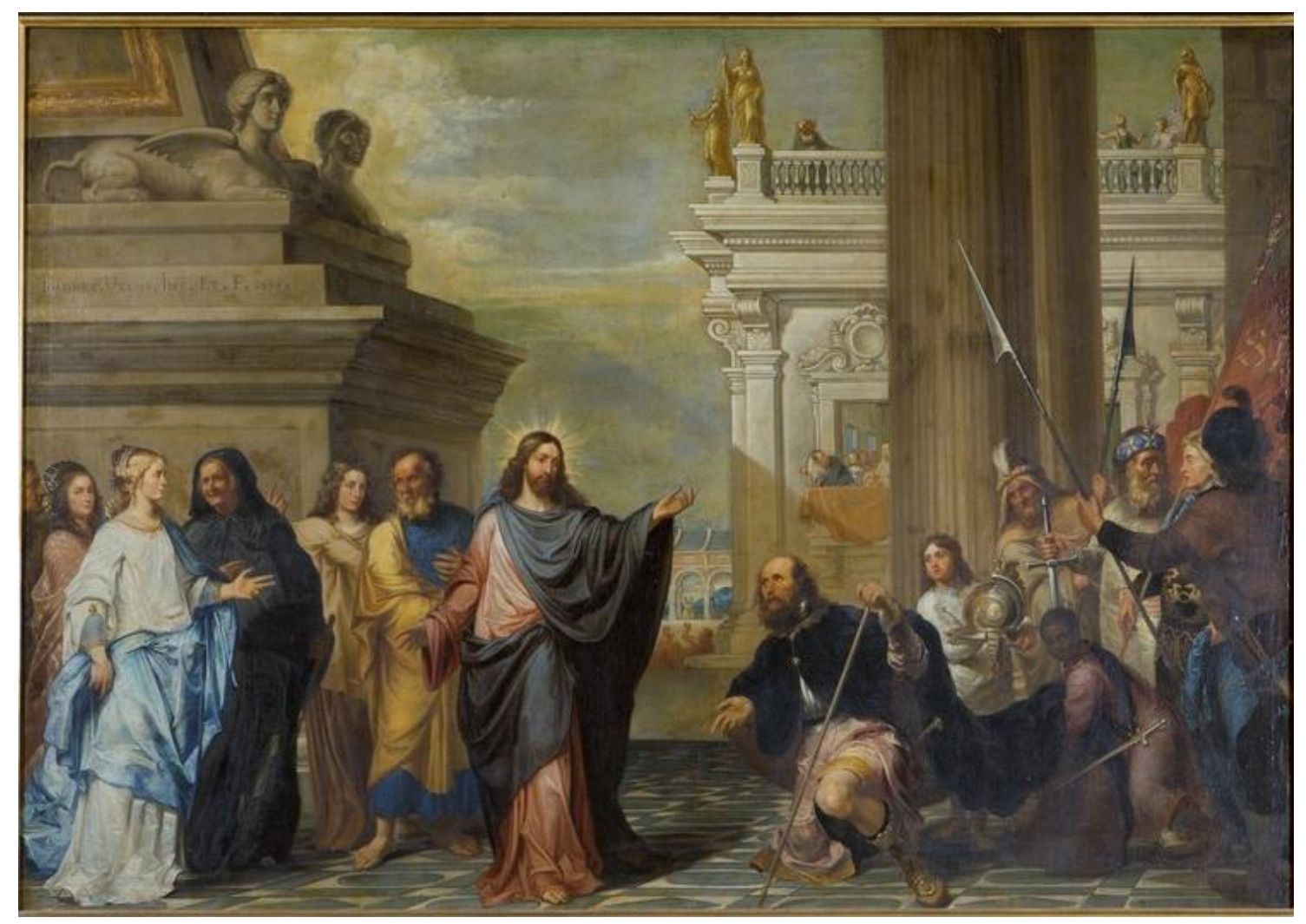

Fig. 2. Jan Ykens, El centurion de Cafarnaún pidiendo a Jesús que cure a su siervo, 1651. Lier, iglesia de Santa Margarita (OKIK-IRPA, Brussels (Belgium), cliché X069322)

composiciones de su producción que hemos podido cotejar, como en El centurión de Cafarnaún pide a Jesús que cure a su siervo, en la iglesia de Santa Margarita de Lier, firmada y fechada en 1651; (Fig. 2) Natán y Batseba suplican al rey David la sucesión de Salomón, también firmada y fechada en los años 70 del siglo XVII, en colección privada7; y la gran Glorificación alegórica del nacimiento de un príncipe ${ }^{8}$, (Fig. 3) firmada y fechada en 1659 , y conservada en el Koninklijk Museum voor Schone Kunsten de Amberes (inv. 795), cuyo dibujo localizamos en el Museo Cerralbo de Madrid ${ }^{9}$. El sentimiento teatral y la personalidad de Jan Ykens en estas obras es igualmente evidente en la pintura que hoy estudiamos.

Menos interés en la concepción formal de la producción del pintor tiene $L a$ entrada de la reina de Saba en Jerusalén ${ }^{10}$, en colección privada. Sin embargo, destaca la acción de un paje sosteniendo la larga cola de la capa de la reina. Es una fórmula que está tomada de tantas adoraciones de los Reyes Magos de Rubens y está presente en el centro de la obra aquí estudia-

\footnotetext{
7 (L. $170 \times 240$ cm.) Roma, Christie's, (22-V-1980, no 284).

8 L. $168,3 \times 233 \mathrm{~cm}$.

${ }^{9}$ Consuelo Sanz Pastor, Museo Cerralbo. Catálogo de dibujos, (Madrid: Comisaría Nacional de Museos y Exposiciones, 1976), no 181.

10 L. $141,5 \times 164 \mathrm{~cm}$.
} 


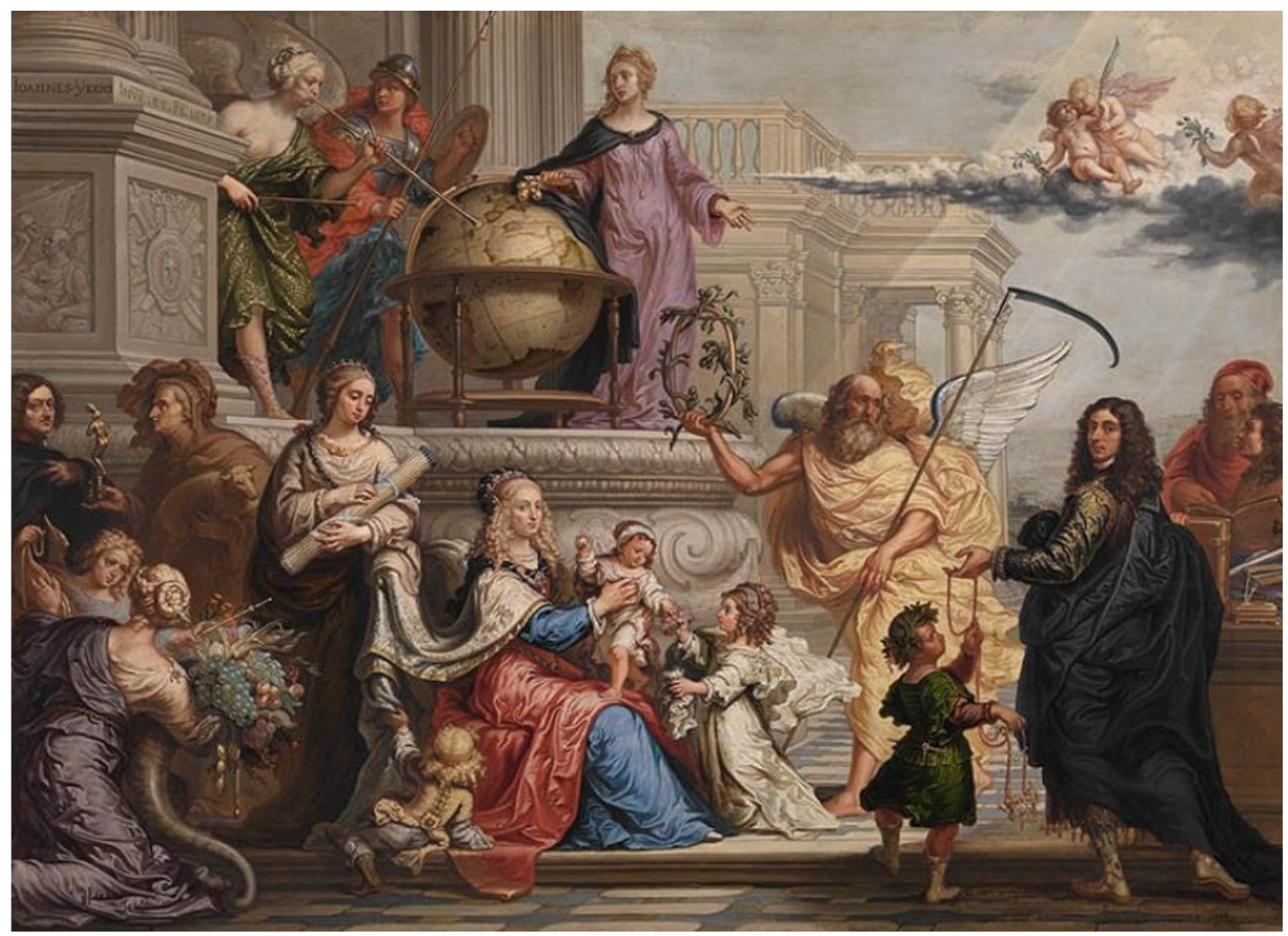

Fig. 3. Jan Ykens, Glorificación alegórica del nacimiento de un príncipe, 1659. Amberes, Koniklijk Museum voor Schone Kunsten $\odot$

da, donde una joven también sujeta el manto de una reina y, frente a ellas, en equilibrada simetría, un paje hace lo propio con el manto del soldado laureado. Es una fórmula que Jan Ykens repite en muchas composiciones.

El escenario arquitectónico, la escultura y la pintura comparten el protagonismo teatral de la narrativa en este espectacular episodio. Los ornamentos se mantienen en equilibrada armonía con el imponente grupo escultórico de las Tres Gracias que domina el eje. Interesa recordar que tanto la arquitectura como la escultura forman parte del sentimiento estético de este pintor formado por su padre, un notable escultor del momento, como ya se adelantó.

La secuencia de la historia de Alejandro Magno representada en este lienzo está inspirada en los textos de Plutarco y Quinto Curcio Rufo ${ }^{11}$, entre otros. A los pies del bronce de las Tres Gracias danzando está una reina, a la que identificamos como Estatira, esposa y hermana de Darío III Codomano, rey de Persia. Es el momento en que ella recibe a Alejandro y a su séquito. El emperador viste una rica armadura, corona de laurel y el clásico manto rojo

11 Plutarco, Las vidas paralelas, t. IV, 1822 (En web: http://cdigital.dgb.uanl.mx/la/1080026188 C/1080026188 T4/1080026188 MA.PDF, consultada: 27-II2019); Quinto Curcio Rufo, Historia de Alejandro Magno, (En web: https://drive.google.com/file/d/1BXIBgU9QLGXMZQ27JlsSV0OU 4goadKZ/view, consultada: 30-I-2019). 
propio de su estatus. Un joven paje sostiene este manto, como es frecuente en composiciones de aparato de Rubens. Este detalle de la etiqueta cortesana, como comentamos en los juicios generales al estilo de Ykens, es muy personal y típico de sus obras de asunto histórico. Así lo vemos en Natán y Bat-seba suplican al rey David la sucesión de Salomón, al igual que en La entrada de la reina de Saba en Jerusalén.

Entre los soldados de rango que acompañan a Alejandro, destaca uno con rica coraza, manto recogido a la cintura y cabeza cubierta con un elegante sombrero negro de plumas rojas. Evocando las esculturas clásicas, este oficial está en equilibrado contraposto. Descansa el cuerpo en su pierna derecha y apoya la mano del mismo lado en un bastón de mando, mientras que con la izquierda sujeta la espada y el escudo de guerrero. Es Hefestión, el máximo hombre de confianza de Alejandro y General de sus ejércitos. La comitiva se completa con otros guerreros en la penumbra de una columnata, a la derecha del espectador.

Estatira espera suplicante la reacción de los victoriosos en la guerra. A su izquierda, una joven coloca un cojín en el suelo, adelantándose al reclinar de la reina, al mismo tiempo que otra deposita la rica y pesada cola del manto en el pavimento, atenta a las indicaciones de una anciana situada en la penumbra. Pensamos que las dos jóvenes son Barsine-Estatira y Dipetris, princesas de Persia, a quienes acompaña su abuela Sisigambis, madre de Darío y suegra de Estatira.

En el lado izquierdo de la historia se suceden personajes en distintos planos. Al fondo, varios cipreses se alinean en perspectiva, contribuyendo a equilibrar la vertical arquitectura del primer plano a la derecha. Este fondo compite en belleza con el brillante acontecimiento de este lienzo. La escena se enmarca en una arquitectura de ricas columnas pareadas y de capitel compuesto, que sustentan el friso y el arquitrabe culminados en una balaustrada de singular distinción, acentuando el sentido teatral de la composición. Todo un derroche del legado renacentista. Desde la balaustrada, varios grupos contemplan curiosos el desarrollo del encuentro.

Lo que aquí se conmemora es la visita de Alejandro a la familia de Darío tras la batalla de Issos, en la que el rey persa resultó vencido. Darío se vio obligado a la retirada y tanto sus posesiones como su familia quedaron a merced de Alejandro. Éste decidió visitar a las mujeres en compañía de Hefestión y, a juzgar por lo recogido en las fuentes, era fácil equivocar al emperador con el gallardo guerrero. Los textos relatan que fue Sisigambis quien encabezó el gesto de pleitesía hacia los dos hombres y confundió sus identidades. Sin embargo, las pinturas de este mismo tema representan a Estatira en esta situación:

Habiendo, pues, cumplido Alejandro con todas aquellas obligaciones de piedad, envió a avisar a las reinas que pasaba a visitarlas, y haciendo retirar a todos los que le acompañaban entró en la tienda solo con Hefes- 


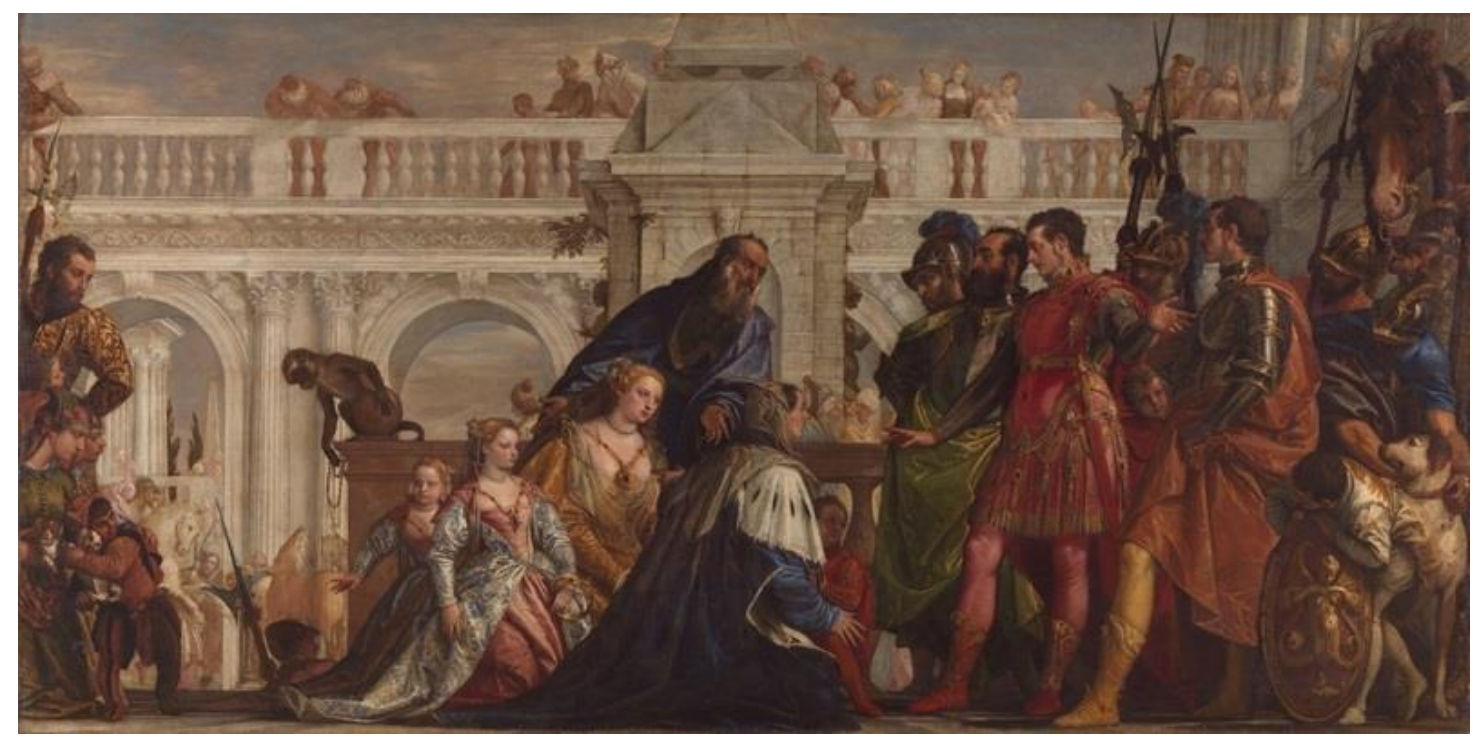

Fig. 4. Paolo Veronese, La familia de Darío delante de Alejandro, 1565-1567. Londres, National Gallery (inv. $\mathrm{n}^{\circ}$ NG294)(

tión. Era valido suyo, y habiéndose criado juntos, tan dueño de su confianza y de su afecto, que no había persona que se atreviese a hablarle con la libertad que él; si bien lo hacía con tal cordura, que más parecía permisión del rey que licencia suya. Eran de una misma edad; pero de tanto mejor disposición y gentileza Hefestión, que teniéndole por rey aquellas princesas, le saludaron y reverenciaron como a tal. Advertidas empero de su equivocación por algunos eunucos cautivos, se arrojó Sisigambis a los pies de Alejandro, dando por disculpa de su yerro el ser la vez primera que le veía. A cuyo tiempo, levantándola el rey y tratándola con el título de madre suya la dijo: Que no le había padecido, por ser Hefestión otro Alejandro. ${ }^{12}$

La luz cae sobre la reina, forjando un dramático contraste con la oscuridad en la que está sumido el grupo de las Tres Gracias. Estatira tiene un especial protagonismo en esta escena. La información que de ella conocemos se reduce a lo narrado por Plutarco y Quinto Curcio Rufo, quienes la describieron como una mujer de gran hermosura y muy amada por su esposo ${ }^{13}$.

Las Tres Gracias portan una dorada corona de laurel que ofrecen a Alejandro, una surrealista acción que hace de esta escultura una realidad vi-

12 Curcio Rufo, Historia de Alejandro Magno, p. 17. Este asunto también fue tratado por Diodoro Sículo, Bibliotheca Historica, XVII, (Madrid: Gredos, 2012), pp. 237-243. (En web: https://dlscrib.com/queue/biblioteca-hist-oacute-rica-libros-xv-xvii-biblioteca-cl-aacute-sica-gredosdiodoro-de-sicilia 58f202e5dc0d60870eda982f pdf?queue id=59936048dc0d60f646300d1a, consultada: 27-II-2019); Publio Valerio Máximo, Hechos y dichos memorables, IV, (Madrid: Gredos, 2003), pp. 322, 323. (En web: https://kupdf.net/download/311-hechos-y-dichos-memorables-libros-i-vivalerio-maxipdf 5994ab67dc0d60d954300d17 pdf, consultada: 27-II-2019); y Flavio Arriano; trad. Alura González, Anábasis de Alejandro Magno, II, pp. 58-61 (En web: http://akropolis.es/wpcontent/uploads/2016/09/ARRIANO-Anabasis-Alejandro.pdf, consultada: 27-II-2019).

13 Plutarco, Vidas paralelas, pp. 42-43; Curcio Rufo, Historia de Alejandro Magno, p. 16. 


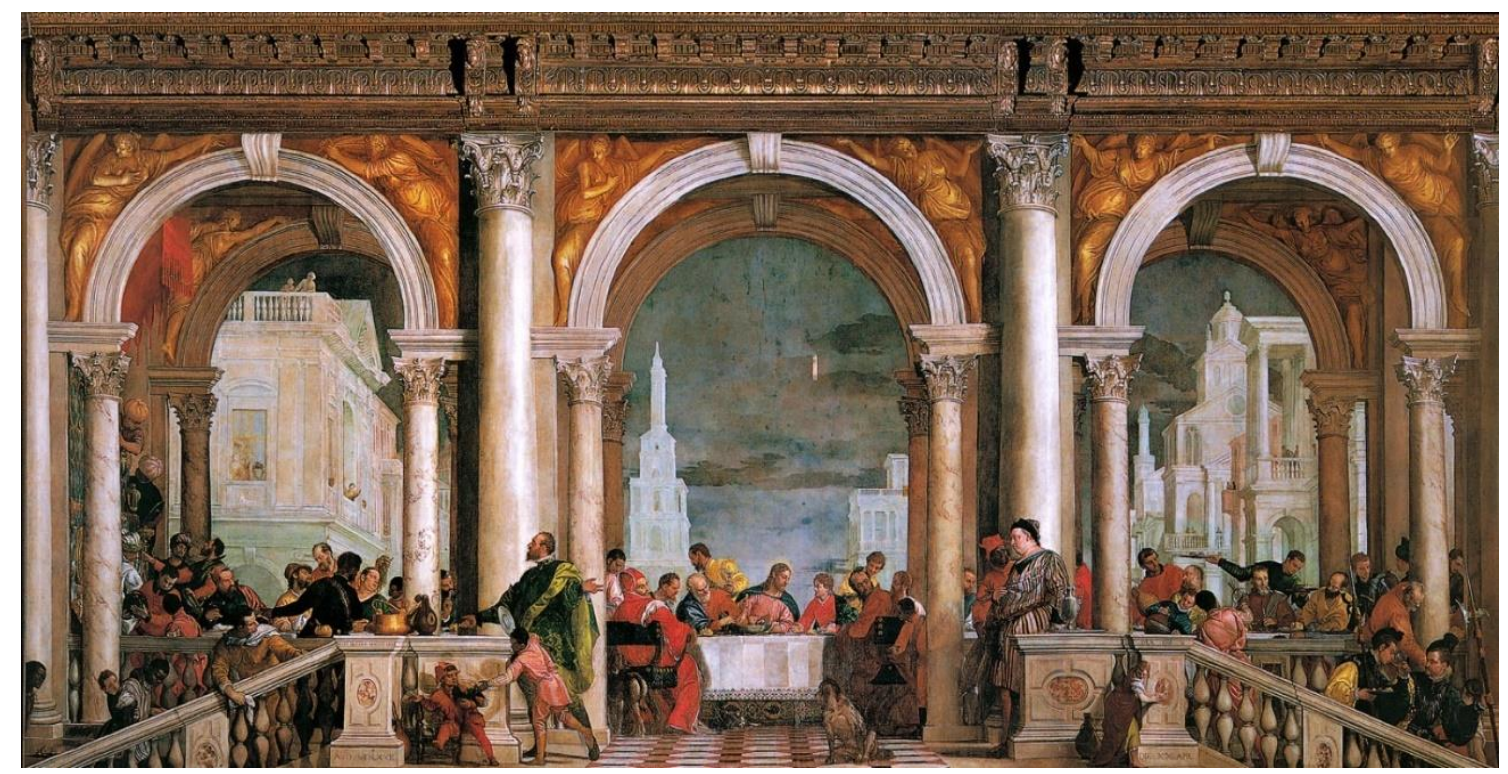

Fig. 5. Paolo Veronese, La cena en la casa de Leví, 1573. Venecia, Accademia di Bele Arti@

viente, en diálogo con el emperador griego. Especialmente interesante y es la evidente dependencia de esta pintura al arte veneciano, sobre todo a Veronés. El estilo compositivo de Jan Ykens y esta pintura en concreto son una singularidad en la pintura flamenca, pues pocos maestros del siglo XVII escapan a la poderosa influencia de Rubens que domina la primera mitad del siglo.

El lienzo retoma fórmulas de una pintura de Veronés del mismo asunto, conservada en la National Gallery de Londres desde mediados del siglo XIX (inv. NG294) ${ }^{14}$, cuando ésta la adquirió de la casa Pisani de Venecia. (Fig. 4) La obra fue citada por Ridolfi en 1648 como La constancia de Alejandro y se conocen varias copias y estudios documentados de los siglos XVIII y XIX ${ }^{15}$.

En la versión de Veronés, la madre de Dario III, Sisigambis, está arrodilla de espaldas al espectador, dirigiendo la mirada hacia los guerreros griegos. A su lado están Estatira, Barsine-Estatira y Dipetris, esposa e hijas del vencido monarca persa. Las acompaña el sirviente que, según las fuentes, advirtió a Sisigambis de haber confundido a Hefestión con Alejandro. Tanto en esta obra del maestro italiano como en la de Ykens que estudiamos, el punto de vista se sitúa bajo. El entorno arquitectónico es frecuente en pinturas del veneciano, tales como Los santos Marco y Marceliano exhortados al martirio por San Sebastián y El martirio de San Sebastián en la capilla mayor de la Iglesia de San Sebastián de Venecia, con la multitud excesivamente abigarrada ${ }^{16}$. Aún más patente es la influencia de los arcos de

\footnotetext{
${ }^{14}$ L. $236,2 \times 474,9 \mathrm{~cm}$.

${ }^{15}$ Remigio Marini, La obra pictórica completa de Veronés, (Barcelona: Noguer, 1976), p. 109, nº128.

16 Marini, Obra pictórica completa, pp. 106-107, no 102 y 103.
} 
La cena en la casa de Leví, en las Galerías de la Academia de Venecia ${ }^{17}$ (inv. 203), pintada para el refectorio del convento de los dominicos de los Santos Juan y Pablo en Venecia ${ }^{18}$. (Fig.5)

Jan Ykens debió de conocer un original o las copias de la pintura de Veronés con la visita de Alejandro a la familia de Darío III. El fondo palaciego tan prodigado por estos dos pintores está lejos de responder a la naturaleza del lugar donde se produjo aquel encuentro, pues las fuentes documentales nos dicen que fue en una tienda de campaña ornamentada con ricos tapices, tal como lo representó Jacob Jordaens con mayor acierto histórico ${ }^{19}$.

A la magnificencia teatral del conjunto de Ykens, se suman la exquisitez de su factura, la riqueza cromática y la sensual valoración del claroscuro. La belleza y el alargamiento de los modelos, en extremo estilizados, son típicos recursos del pintor. Es genial la táctil captación del metal de las corazas y de las armas, en oposición a la suavidad de las túnicas y mantos que visten los hombres y las mujeres. Entona con acierto los colores cálidos y los fríos, con acentos vivos y centellantes de luz en un correcto dibujo.

\footnotetext{
17 L. $555 \times 130 \mathrm{~cm}$.

18 Marini, Obra pictórica completa, p. 114, no 164.

19 Matías Díaz Padrón, Jacob Jordaens y España, t. II, (Madrid: Epiarte, Instituto Moll, 2018), p. 413.
} 
Bibliografía:

Arriano 2012-2013: Flavio Arriano; trad. Alura González, Anábasis de Alejandro Magno, II, pp. 58-61. (En web: http://akropolis.es/wpcontent/uploads/2016/09/ARRIANO-Anabasis-Alejandro.pdf, consultada: 27II-2019).

Bodson 1995: Bernadette Bodson, "Ykens Jan (Ijkens) Anvers, 1613 - après 1679", en VV.AA., Le Dictionnaire des Peintres Belges du XIVe siècle à nos jours. L-Z, (Bruxelles: La Renaissance du Livre, 1995).

Curcio Rufo: Quinto Curcio Rufo, Historia de Alejandro Magno. (En web: https://drive.google.com/file/d/1BXIBgU9QLGXMZQ27JlsSV0OU 4goadKZ/vi ew, Consultada: 30-I-2019).

Dhanens 1961: Elisabeth Dhanens, Inventaris van het kunstpatrimonium van de provincie Oost-Vlaanderen, Temse, IV, (Gent: Dendermonde, 1961).

Díaz Padrón 2018: Matías Díaz Padrón, Jacob Jordaens y España, t. II, (Madrid: Epiarte, Instituto Moll, 2018), p. 413.

Diodoro Sículo 2012: Diodoro Sículo, Bibliotheca Historica XVII, (Madrid: Gredos, 2012), pp. 237-243, (En web: https://dlscrib.com/queue/bibliotecahist-oacute-rica-libros-xv-xvii-biblioteca-cl-aacute-sica-gredos-diodoro-desicilia 58f202e5dc0d60870eda982f pdf?queue id=59936048dc0d60f64630 Od1a, consultada: 27-II-2019).

De Maere y Wabbes 1994: Jan de Maere \& Marie Wabbes, Illustrated dictionary of the 17th century flemish painters, II, (Bruxelles: La Renaissance du Livre, 1994).

Duverger 1999: Erik Duverger, Antwerpse Kunstinventarissen uit de Zeventiende Eeuw, 10, Fontes Historiae Neerlandicae, (Brussel: 1999).

Marini 1976: Remigio Marini, La obra pictórica completa del Veronés, (Barcelona: Noguer, 1976), p. 109, n0128.

Nederlands Instituut voor Kunstgeschiedenis: RKD - Nederlands Instituut voor Kunstgeschiedenis, "Johannes Ykens" (En web: https://rkd.nl/nl/explore/artists/record?query=Jan+Ykens\&start=7 consultada: 1-III-2019).

Plutarco 1822: Plutarco, Las vidas paralelas, t. IV, 1822. (En web: http://cdigital.dgb.uanl.mx/la/1080026188 C/1080026188 T4/1080026188 MA.PDF, consultada: 27-II-2019).

Rombouts y Van Lerius 1864-1876: Philippe Rombouts y Théodore van Lerius, Les Liggeren et autres archives historiques de la Gilde Anversoise de Saint Luc, II, (Anvers-La Haye, 1864-1876). 
Sanz Pastor 1976: Consuelo Sanz Pastor, Museo Cerralbo. Catálogo de dibujos, (Madrid: Comisaría Nacional de Museos y Exposiciones, 1976), no 181.

Valerio Máximo 2003: Publio Valerio Máximo, Hechos y dichos memorables, IV, (Madrid: Gredos, 2003), pp. 322, 323, (En web: https://kupdf.net/download/311-hechos-y-dichos-memorables-libros-i-vivalerio-maxipdf 5994ab67dc0d60d954300d17 pdf, consultada: 27-II2019).

Witlox 2005: Maartje Witlox, "Vele handem maken licht werk", Mauritshuis in Focus, 1, vol. 18, (2005), pp. 16-26.

Recibido: 2/05/2019

Aceptado: 17/05/2019 